\title{
PROTEIN BIOTOXINS OF MILITARY SIGNIFICANCE
}

\author{
Jiři Patočka ${ }^{1}$, Ladislav Středa ${ }^{2}$
}

University of Defence, Faculty of Military Health Sciences, Czech Republic: Department of Toxicology ${ }^{1}$; University of South Bohemia, Faculty of Health and Social Studies, Czech Republic: Department of Radiology and Toxicology ${ }^{1}$; State Office for Nuclear Safety, Czech Republic: Department for Control of the Prohibition of Chemical Weapons ${ }^{2}$

Summary: There is a spectrum of several threat agents, ranging from nerve agents and mustard agents to natural substances, such as biotoxins and new, synthetic, bioactive molecules produced by the chemical industry, to the classical biological warfare agents. The new, emerging threat agents are biotoxins produced by animals, plants, fungi, and bacteria. Many types of organisms produce substances that are toxic to humans. Examples of such biotoxins are botulinum toxin, tetanus toxin, and ricin. Several bioactive molecules produced by the pharmaceutical industry can be even more toxic than are the classical chemical warfare agents. Such new agents, like the biotoxins and bioregulators, often are called mid-spectrum agents. The threat to humans from agents developed by modern chemical synthesis and by genetic engineering also must be considered, since such agents may be more toxic or more effective in causing death or incapacitation than classical warfare agents. By developing effective medical protection and treatment against the most likely chemical and mid-spectrum threat agents, the effects of such agents in a war scenario or following a terrorist attack can be reduced. Toxin-mediated diseases have made humans ill for millennia. Unfortunately, the use of biological agents as weapons of terror has now been realized, and separating naturally occurring disease from bioterroristic events has become an important public health goal. The key to timely identification of such attacks relies on education of primary care physicians, first responders, and public health officials.

Key words: Biotoxin; Terrorism; Toxic protein; Ricin; Abrin; Viscumin; Volkenesin; Modeccin; Conotoxin; Botulinum toxin; Clostridium perfringens toxins; Diphteriae toxin; Staphylococcus toxin; Shigatoxin; Verotoxin, Cholera toxin; Tetanus toxin; Microcystin

\section{Introduction}

Toxin-mediated diseases have made humans ill for millennia. They also have been used in beneficial ways. Unfortunately, the use of biological agents as weapons of terror has now been realized, and separating naturally occurring disease from bioterroristic events has become an important public health goal. The key to timely identification of such attacks relies on education of primary care physicians, first responders, and public health officials.

Natural toxins are toxic compounds produced by living organism. There are principle toxic substances of poisonous animals, plants, microorganisms and other forms of life. The manner of their toxic effect can be very different in individual substances. According to the organ toxicity we distinguish neurotoxins, hepatotoxins, nephrotoxins, hemotoxins etc. For example neurotoxins are toxic agents or substances that inhibit, damages or destroys the tissues of the nervous system, especially neurons, the conducting cells of your body's central nervous system. Neurotoxic effects can include behavior changes, seizures, as well as wide range of effects, including death. According to the chemical structure it is possible to divide all natural toxins (biotoxins) into nonprotein and protein compounds.

Chemical Weapons Convention (CWC) (1993) includes toxins as chemical agents, and specifically includes toxins in its control regime along with other highly toxic chemicals. There are these protein toxins: Abrin, botulinum toxins, Clostridium perfringens toxins, Corynebacterium diphteriae toxin, microcystins, Staphylococcus aureus toxin, ricin, shigatoxin, and tetanus toxin. On the „control list“ of the Australian Group, voluntary asssociation of 33 countries ${ }^{1}$ established in 1985, also conotoxins, verotoxin, cholera toxin, modeccin, volkensin and viscumin are enregistered. Biotoxins have been employed in warfare and in terrorist

${ }^{1}$ The 33 states participating in the Australia Group are Argentina, Australia, Austria, Belgium, Bulgaria, Canada, Cyprus, Czech Republic, Denmark, Finland, France, Germany, Greece, Hungary, Iceland, Ireland, Italy, Japan, Luxembourg, the Netherlands, New Zealand, Norway, Poland, Portugal, Romania, Slovakia, South Korea, Spain, Sweden, Switzerland, Turkey, United Kingdom, and United States. The European Commission also participates. Several other countries, including Russia, Ukraine, India, and China, have national export controls for some, but not all, of the items on the group's lists. 
attacks (61). Botulinum toxin produces a descending flaccid paralysis. Staphyloccocal enterotoxin B produces a syndrome of fever, nausea, and diarrhea and may produce a pulmonary syndrome if aerosolized. Clostridium perfringens epsilon-toxin could possibly be aerosolized to produce acute pulmonary edema. Ricin intoxication can manifest as gastrointestinal hemorrhage after ingestion, severe muscle necrosis after intramuscular injection, and acute pulmonary disease after inhalation (21). All these biotoxins may be perilous if will misuse by terrorists (67). A brief review of nonprotein biotoxins has been published recently (51). This review covers peptide toxins which are on the „control list“ of chemical weapons. Each toxin is briefly characterized chemically, pharmacologically and toxicologically. Their natural sources, availability, stability, and military potential are discussed.

\section{Chemical classification of protein toxins}

All peptide toxins are created by one of more linear or cyclic polypeptide chains. That polypeptide is constructs from more amino acids connected by means of peptide linkage.

Proteins are large macromolecules composed of one or more peptide chain. It is possible to say that polypeptides composed from less number of amino acids are designated as peptides or polypeptides, from the larger number as proteins. The crossover between peptides and proteins is not defined exactly and is unsubstantial from practice point of view.

\section{Biotoxins as chemical weapons of warfare and terrorism}

Biotoxins can be employed in warfare and in terrorist attacks. In this era, it is imperative that health care providers are familiar with illnesses caused by these agents. Botulinum toxin produces a descending flaccid parakusis (50). Staphyloccocal enterotoxin B produces a syndrome of fever, nausea, and diarrhea and may produce a pulmonary syndrome if aerosolized. Clostridium perfringens epsilon-toxin could possibly be aerosolized to produce acute pulmonary edema. Ricin, abrin and other plant protein toxin intoxication can manifest as gastrointestinal hemorrhage after ingestion, severe muscle necrosis after intramuscular injection, and acute pulmonary disease after inhalation. Health care providers should be familiar with the medical consequences of toxin exposure, and understand the pathophysiology and management of resulting illness (21).

\section{Plant toxins}

Plant toxic proteins belong to a group of phytotoxins, which inhibit the protein synthesis of eukaryotic cells. The toxins of this group are glycoproteins with molecular weights of about $60 \mathrm{kDa}$ which consist of two subunits linked into a dimer by a disulfide bond. One of the subunits is lectin with sites for carbohydrate binding (B-chain), and the other subunit is specific N-glycosidase (A-chain), which modifies the $28 \mathrm{~S}$ rRNA-60S ribosomal subunit (23). The group of proteins known as the lectins was first recognised in plant seeds and they bind to specific sugars. Although lectins, in general, are not very toxic, there are some relationships between lectins and toxins (66). They may also serve as recognition markers in cellular differentiation and act as immunotoxin. Only A-chain is toxic due to inhibiting protein synthesis. The A-chain catalytically inactivates $60 \mathrm{~S}$ ribosomal subunit by removing adenine from positions 4 and 324 of $28 \mathrm{~S}$ rRNA. Ribosome-inactivating proteins (RIP) have been identified in many plants and some of them are very toxic, but only in connection with B-chain. The A-chain is carrier of toxicity, but B-chain binds to cell surface receptors and facilitate a transport of the A-chain across the cell membrane. The A-chain is not active until it internalized by the cell, where halts protein synthesis(63). Each toxin molecule can disable approximately 2000 polysomes per minute, enough to eventually kill the cell. The most known plant toxic proteins of this type are ricin, abrin, modessin, viscumin and volkensin $(47,51)$.

\section{Ricin}

Ricin is a protein produced by the castor oil plant, Ricinus communis. It is native to tropical Africa, but has naturalised sub-tropical and temperate areas as well. The whole of the plant is poisonous, containing the toxin ricin, which reaches the highest levels in the seeds. The seeds also contain a purgative oil, the triglyceride of ricinoleic acid. The seeds have been used in folk medicine against many diseases for centuries.

Ricin is the compound responsible for toxicity of the seeds of $R$. communis (58). Ricin has been known as a poison for years, usually through livestock deaths. One to three seeds may be fatal to a child; two to four may be poisonous to an adult, while eight may be fatal. A fatal ingested dose for human is about $1 \mu \mathrm{g} / \mathrm{kg}$ (10). Because the alimentary tract destroys lots of ricin, it is much more potent when administered paraenterally. The toxically active A-chain of ricin is a 267 amino acid globular protein and is classed as an $\mathrm{N}$-glycosidase. The A-chain is protein containing 8 alpha helices and 8 beta sheets $(29,39)$. The B-chain is composed of 262 amino acid residues and is classed as a lectin (29). The B chain has an affinity for bindig to galactosides (58) and posseses two galactose binding sites that are attracted to galactose containing glycoproteins at the cell surface. The A- and B-chain glycoproteins are linked by a disulfide bond located at residue 259 of the A-chain and residue 4 of the B-chain (38). Ricin is a glycoprotein with carbohydrate side chains in the form of mannose-rich N-linked oligosaccharides and particularly binds to mannose receptors of cells of the reticuloendothelial system. The specific sites with potential for binding of high mannose carbohydrate chains of ricin are at asparagines 10 and 236 of the A-chain, and asparagines 95 and 135 of the B-chain (58). 
The toxic effects of ricin are essentially the result of the action of the A-chain, which inactivates the ribosomes of the cell. It is thought that the B-chain serves to bind to galactose-containing and/or mannose-containing structures at the cell surface thus allowing the A-chain to enter the cell (44). By this way the protein is internalized, meaning that it is taken into the cell as a toxin-binding site complex in vesicles. The B-chain of ricin facilitates the escape of the A-chain by binding to the endosomal membrane allowing the A-chain to pass through the membrane. Then, the Bchain dissociates from the A-chain by breaking the disulfide bond. The A-chain is thus delivered to the cytoplasm where it is taken up by the Golgi apparatus and transported to the endoplasmic reticulum (44).

At the endoplasmatic reticulum, ricin inactivates the cell ribosomes by elimination of adenine in specific RNA sequences on the $28 \mathrm{~S}$ ribosomal subunit (33). A single A-chain molecule is capable of deactivating every ribosome in the cell thus halting protein synthesis and culminating in cell death. It is important to note that the toxin is specific for eukaryotic ribosomes. A hairpin loop on the $28 \mathrm{~S}$ rRNA containing the tetranucleotide loop GAGA is the most likely target for attack by ricin on the ribosome, however it is thought that the ribosome conformation is an important factor in recognition by the protein (33). Therefore, ricin is not a nucleotide sequence-specific protein.

Ricin is the only toxin to exist naturally in large quantities. It is a byproduct of castor oil production and ricin isolation is a simple and cheap separation. Easy preparation and low price might make this toxin attractive to poor country. For nations or terrorists who lack the money to spend on nuclear weapons and other high-tech killing instruments, toxin warfare offers horrific appeal: biological/ toxin weapons are cheap, easy to make, and simple to conceal. Even small amounts, if effectively used, could cause massive injuries and make many suffer (54). Ricin's significance as a potential biological warfare toxin relates in part to its wide availability. Worldwide, one million tons of castor beans are processed annually in the production of castor oil and in the waste is five percent ricin by weight. The toxin is also quite stable and extremely toxic by several routes of exposure, including the respiratory route (53).

In biological warfare it is expected that ricin would be released as a toxic cloud. It could also be injected into specific persons as a terrorist or sabotage weapon. Additionally, ricin is easy to produce and is stable. The toxic effects of ricin occur because it kills the cells of the body that it contacts when it is taken into the body. Upon inhaling an adequate amount of ricin, death of persons affected would be expected in 36-48 hours because of difficulty breathing and circulatory system effects. Ingested ricin is expected to cause internal bleeding, death of vital organs and death of the individual. Injected ricin causes death by major organ failure.

The prediction of symptoms to be expected is based on animal studies and accidental human exposures, which were not fatal. Symptoms would probably vary depending on whether ricin was inhaled, ingested or injected. About three hours after inhaling ricin, the symptoms expected are cough, tightness of the chest, difficulty breathing, nausea and muscle aches. This would progress to a severe inflammation of the lungs and airways, increased difficulty breathing, cyanosis and death in 36-48 hours from failure of the breathing and circulatory systems. Ingestion of ricin would be expected to cause nausea and vomiting, internal bleeding of the stomach and intestines, failure of the liver, spleen and kidneys and death of the individual by collapse of the circulatory vessels. No specific affects on the lungs and airways would be expected. If injected, ricin causes marked death of muscles and lymph nodes near the site of injection and probable failure of major organs and death of the individual (52).

\section{Abrin}

Abrin is a potent toxin that has been isolated from the seeds of Abrus precatorius (or Rosary pea). Its use as a tool for research was described in 1972 by Sharon and Lis (60). Abrin exists in two forms, abrin a and abrin b. Both are composed of two chains, an A-chain and a B-chain. A disulfide bond between Cys247 of the A-chain and Cys8 of the B-chain links the A and B chains. The A-chain is 251 residues and is divided into 3 folding domains. The A-chain catalytically inactivates $60 \mathrm{~S}$ ribosomal subunits by removing adenine from positions 4 and 324 of $28 \mathrm{~S}$ rRNA therefore inhibiting protein synthesis. The B-chain is a galactose specific lectin that facilitates the binding of abrin to cell membranes $(7,45)$. The B-chain of both forms of abrin consists of 268 amino acid residues and shares 256 identical residues. Comparison of their sequences with that of the ricin's B-chain shows that $60 \%$ of the residues of abrin's B-chain are identical to those of the ricin's B-chain and that two saccharide-binding sites in ricin B-chain identified by a crystallographic study are highly conserved in abrin Bchain (30).

The mechanism of toxic action of abrin is identical to that of ricin (53) but the toxicity of abrin in mice is 75 times higher that of ricin $(0.04 \mu \mathrm{g} / \mathrm{kg}$ for abrin compared to 3 $\mu \mathrm{g} / \mathrm{kg}$ for ricin). The diagnosis, clinical features, treatment, protection, prophylaxis and so on is also the same for both abrin and ricin intoxications $(46,48)$.

\section{Viscumin}

Viscumin (Mistletoe lectin I, ML I), inevitable to the family of RIPs, was identified in the late 1980s as the main pharmacologically-active ingredient of mistletoe (Viscum album) extract and is largely responsible for its toxicity (31). It is comparable in toxicity to ricin and acts by the same mechanism. When viscumin binds to its target cell, protein synthesis in that cell is interrupted as a result of the Achain's enzymatic activity, like a ricin. This interruption induces a cellular stress response, which triggers the release of cytokines by the target cell and, at high viscumin con- 
centrations, apoptosis of the cell. The association of A- and B-subunits is predominantly hydrophobic in nature.

\section{Volkensin}

Volkensin is a lectin from Adena volkensii (the kilyambiti plant) that is comparable in toxicity to ricin and that acts by the same mechanism (a ribosome-inactivating protein) (6). The plant is a relatively unattractive and toxic succulent plant found in Africa that appears to be of little interest. However, it has proven useful as a research reagent in neurology because of its ability to be taken up and transported by certain types of nerve. There may be pressure to develop commercial sources for the research community (52).

\section{Modeccin}

Modeccin is a lectin from the roots of Adenia digitata an African succulent plant that is comparable in toxicity to ricin (43) and acts by the same mechanism $(46,56)$. The plant does not seem to have any significant uses, such as a food or medicine and so is not available in quantities comparable to abrin, let alone ricin. However, the seed does seem to be readily available. The subunits of modeccin were isolated (subsequently referred to as modeccin 4B), purified from the roots of Adenia digitata by affinity chromatography on Sepharose 4B (17). They are an A subunit (mol. wt. 26 000), which inhibits protein synthesis, and a B subunit (mol.wt. 31 000), which binds to cells. A second form of modeccin, not retained by Sepharose 4B, was purified by affinity chromatography on acid-treated Sepharose 6B: this form is subsequently termed modeccin 6B. Modeccin $6 \mathrm{~B}$ has a molecular weight indistinguishable from that of modeccin 4B, and consists of two subunits of mol.wts. 27 000 and 31000 , joined by a disulphide bond. The subunits were not isolated because of their high insolubility in the absence of sodium dodecyl sulphate. As compared with modeccin $4 \mathrm{~B}$, modeccin $6 \mathrm{~B}$ is slightly less toxic to animals, does not agglutinate erythrocytes, and is a more potent inhibitor of protein synthesis in a lysate of rabbit reticulocytes, giving $50 \%$ inhibition at the concentration of $0.31 \mu \mathrm{g} / \mathrm{ml}(2)$.

\section{Animal toxins}

There are numerous protein toxins produced by many different animal sources, such as snakes, scorpions, spiders, insects, frogs, sea anemones etc. Only conotoxins, the toxic principle of marine snails of the genus Conus, are presented on the control list of the Australian Group.

\section{Conus toxins (conotoxins)}

These are toxic peptides produced by the fish-hunting marine snails of the genus Conus. The conotoxins (the snails produce a mixture of toxic substances) are used to paralyse the fish being attacked (32). For centuries members of the Conidae family have been collected for their unique and intricately designed shells. Only during the last few decades have Cone shells become an exciting area for scientific research. Cone shlells are marine snails and are found in reef environments throughout the world. They prey upon other marine organisms, immobilising them with unique venoms. They can be dangerous for human, too. There have been 30 recorded cases of human envenomation by fish-eating cone shells, in some cases fatal (15).

The composition of the venom differs greatly between species and between individual snails within each species, each optimally evolved to paralyse it's prey. The active components of the venom are small peptides toxins, typically 12-30 amino acid residues in lengt. They have very tight conformations by multiple disulfide bridges. These patterns of disulfide bridge help to define a number of structural classes of conotoxin. Today several tens of conotoxins is known and these are divided into four group. Alpha-conotoxins are the shortest and have only two disulfide bridges. Mu-conotoxins, omega-conotoxins, delta-conotoxins, and kappa-conotoxins contain three difulfide bridges between different cysteine residues of peptide chain (42).

The paralytic components of the venom that have been the focus of recent investigation are the alpha, omega and mu-conotoxins. All of these conotoxins act by preventing neuronal communication, but each targets a different aspect of the process to achieve this. The alpha-conotoxins target nicotinic ligand gated channels, the mu-conotoxins target the voltage-gated sodium channels and the omega conotoxins target the voltage-gated calcium channels.

Another class of peptides from Conus venoms are the conantokins, the first peptide antagonists which target to the major excitatory receptors in the vertebrate central nervous system, glutamate receptors. The conantokins selectively inhibit a subtype of glutamate receptor, the N-methyl-

Tab. 1: Individual types of conus toxins and their biological targets.

\begin{tabular}{|l|l|l|}
\hline \multicolumn{1}{|c|}{ alpha } & \multicolumn{1}{c|}{ mu } & \multicolumn{1}{c|}{ omega } \\
\hline $\begin{array}{l}\text { Nicotinic acetylcholine receptors. } \\
\text { The effect is a paralysis similar to } \\
\text { that seen with curare. }\end{array}$ & $\begin{array}{l}\text { Sodium channels. This is also the target } \\
\text { for saxitoxin and tetrodotoxin and the } \\
\text { effects are similar. }\end{array}$ & $\begin{array}{l}\text { Calcium channels associated with } \\
\text { nerve impulse transmission at the } \\
\text { neuromuscular junction. }\end{array}$ \\
\hline $\begin{array}{l}\text { Sodium channels. Unlike mu } \\
\text { conotoxins, they slow the } \\
\text { inactivation of the sodium channel. }\end{array}$ & $\begin{array}{l}\text { Potassium channels. They are also known } \\
\text { as shaker peptides because they block } \\
\text { a potassium channel known as „Shaker“ } \\
\text { and as a result they induce tremors. }\end{array}$ & $\begin{array}{l}\text { NMDA glutamate receptors. } \\
\text { This blocks nerve impulses that use } \\
\text { glutamic acid rather than } \\
\text { acetylcholine as the neurotransmitter. }\end{array}$ \\
\hline
\end{tabular}


D-aspartate (NMDA) receptor, which are ligand-gated Ca channels. The conantokins cause rather striking and till this time little explored biological effects (5).

A short outline of all known conus toxins and their targets is summarized in Table I.

Individual conotoxins, even within the same class can vary greatly in lethality towards mammals. Some of the tremor inducing omega conotoxins are not lethal, whereas others of the same group are lethal at low levels. However, they are only toxic in rats and mice when administered intracranially (into the brain). Some alpha conotoxins have lethal doses as low as $25 \mu \mathrm{g} / \mathrm{kg}$ for mouse. This may be an overestimate of toxicity because it is determined from the dose required to kill a mouse in 20 minutes. In addition, it has to be borne in mind that the toxicity of the complex mixture of peptides that is cone snail venom may be much greater than the sum of its parts because of the synergistic interaction between toxins acting on different aspects of neural function. Incidents of cone snails killing people are known to have occurred.

\section{Microbial toxins}

Protein toxins represent numerous group of toxic compounds, produced by different pathogenic bacteria. These bacterial toxins are in this review: botulinum toxins, Clostridium perfringens toxins, Corynebacterium diphteriae toxin, Staphylococcus aureus toxins, shigatoxin,, verotoxin, cholera toxin, and tetanus toxin.

\section{Botulinum toxins}

Botulinum toxin is derived from the genus of anaerobic bacteria named Clostridia. Seven antigenic types of botulinum toxin exist, designated from A through G (49). They can be identified based on antibody cross reactivity studies. Clostridium botulinum, is a familiar bacterium that causes botulism, a form of food poisoning (8). Naturally occurring botulism is the disease that results from the absorption of botulinum toxin into the circulation from a mucosal surface (gut, lung) or a wound. It does not penetrate intact skin. The toxin irreversibly binds to peripheral cholinergic synapses, preventing the release of the neurotransmitter acetylcholine from the terminal end of motor neurons. This leads to muscle paralysis, and in severe cases, can lead to a need for mechanical respiration (50).

Patients with botulism typically present with difficulty speaking, seeing and/or swallowing. Prominent neurologic findings in all forms of botulism include ptsosis, diplopia, blurred vision, dysarthria and dysphagia. Patients typically are afebrile and do not have an altered level of consciousness. Patients may initially present with gastrointestinal distress, nausea, and vomiting preceding neurological symptoms (57).

Botulinum toxin belongs to thje most dreaded potential biowarfare agents and in this case can be delivered not only as contaminated food and water but also in the form of aerosol, which produces a clinical picture very similar to food-borne intoxication (51).

\section{Clostridium perfringens toxins}

The Gram-positive pathogen Clostridium perfringens is a major cause of human and veterinary enteric disease largely because this bacterium can produce several toxins when present inside the gastrointestinal tract. $C$. perfringens food poisoning is one of the more common in the industrialised world (62). The enteric toxins of $C$. perfringens share two common features: 1) they are all single polypeptides of modest ( $\sim 25-35 \mathrm{kDa})$ size, although lacking in sequence homology, and 2) they generally act by forming pores or channels in plasma membranes of host cells (55). These enteric toxins include $C$. perfringens enterotoxin (CPE), which is responsible for the symptoms of a common human food poisoning and acts by forming pores after interacting with intestinal tight junction proteins. Two other $C$. perfringens enteric toxins, epsilon-toxin (a bioterrorism select agent) and beta-toxin, cause veterinary enterotoxemias when absorbed from the intestine. $C$. perfringens enterotoxin (beta-toxin) has been shown to be the virulence factor responsible for causing the symptoms of $C$. perfringens food poisoning. Beta-toxin is a single polypeptide chain with a molecular weight of $3.5 \mathrm{kDa}$ that binds to receptors on the target epithelial cells. Through a unique four-step membrane action it finally causes a breakdown in normal plasma membrane permeability properties $(4,55)$. Also beta- and epsilon-toxins apparently act by forming oligomeric pores in intestinal or extra-intestinal target tissues. Other C. perfringens toxins have different effect. $C$. perfringens alpha-toxin is able to lyse erythrocytes via calcium channels activation (41). The main biological activity of epsilon-toxin is the production of oedema in various organs and cytoskeletal changes and plasma membrane functional alteration (13).

\section{Corynebacterium diphteriae toxin}

Diphtheria toxin is an extracellular protein of Corynebacterium diphtheriae that inhibits protein synthesis and kills susceptible cells (26). C. diphtheriae is responsible for diphtheria. Diphtheria is a contagious, airborne, toxin-producing infection caused by $C$. diphtheriae. It is characterized by the formation of a gray resistant pseudo-membrane in the lining of the mucous membrane of the upper respiratory tract as well as in the tonsils. Certain forms of the disease may be fatal. The global mortality rate for diphtheria is $5 \%$ to $10 \%$ and may reach $20 \%$ among children under 5 and adults over 40. In 1888, Roux discovered the diphtheria toxin secreted by $C$. diphtheriae, an agent of diphtheria. In 1890, the work of von Behring and Kitasato on antibodies to diphtheria antitoxins made it possible to envision their use in treating the disease (22). In 1897, Ehrlich established a standardized diphtheria toxin. These passive serum therapies would soon lead to active immunization. Diphtheria vaccines were first used in France in the 1920s. Mass immunization only began in the 1950s. The diphthe- 
ria vaccines used today throughout the world against the pathogenic and lethal effects of the diphtheria toxin are obtained by detoxification of the toxoid with formalin.

\section{Staphylococcus toxins}

Staphylococcus aureus is a spherical bacterium (ccocus) which on microscopic examination appears in pairs, short chains, or bunched, grape-like clusters. These organisms are gram-positive. Some strains are capable of producing a highly heat-stable protein enterotoxins, range in size from 19 to $26 \mathrm{kDa}$, that cause illness in humans. Seven immunologically different forms of Staphylococcus enterotoxins is known: A, B, C $1, C_{2}, C_{3}, D$ and $\mathrm{E}$. These toxins are responsible for symptoms of food poisoning that follow consumption of food contamined by Staphylococcus bacteria.

The onset of symptoms in staphylococcal food poisoning is usually rapid and in many cases acute, depending on individual susceptibility to the toxin, the amount of contaminated food eaten, the amount of toxin in the food ingested, and the general health of the victim. The most common symptoms are nausea, vomiting, retching, abdominal cramping, and prostration. Some individuals may not always demonstrate all the symptoms associated with the illness. In more severe cases, headache, muscle cramping, and transient changes in blood pressure and pulse rate may occur. Recovery generally takes two days, However, it us not unusual for complete recovery to take three days and sometimes longer in severe cases.

Infective dose - a toxin dose of less than $1.0 \mu \mathrm{g}$ in contaminated food will produce symptoms of staphylococcal intoxication. This toxin level is reached when $S$. aureus populations exceed 100,000 per gram.

$S$. aureus produce also hemolyticaly active toxins, so called hemolysins. Three hemolysins, alpha toxin, beta toxin, and delta toxin, are known and each of them exist in more molecular forms. Their mechanism of toxic action is different (25).

Alpha toxin, also known as alpha hemolysin, is one of many virulence factors produced by Staphylococcus aureus (16). Alpha toxin is a single polypeptide chain known in four molecular forms with a molecular weight from 26 to $39 \mathrm{kDa}$. The majority of $S$. aureus strains isolated from humans produce this toxin. Alpha toxin has been shown to be lethal in animals, causing respiratory paralysis, vascular and smooth muscle spasms, and tissue necrosis (64).

Beta toxin (beta-hemolysin) is one of several extracellular proteins produced by $S$. aureus. It is a sphingomyelinase which disrupts the membranes of erythrocytes and other mammalian cells. Despite its characterized mechanism of action, the role of beta-toxin in human and animal disease remains unclear (34).

Delta toxin (delta hemolysin) is heat-stable peptide, molecular weight $5 \mathrm{kDa}$, composed from 26 amino acid residues. Its molecule create amphiphatic helix with hydrophilic amino acid residues on one side of long axis of molecule, hydrophobic residues on other side and produced lesions in biological membranes very similar to those produced by melittin and Triton X-100 (16).

\section{Shigatoxin}

Shigella are the most important organisms can cause dysentery. Shigella dysenteriae type $1(\mathrm{Sd} 1)$ is the most virulent of the four serogroups of Shigella. Sd1 is the only cause of epidemic dysentery. In addition to bloody diarrhoea, the illness caused by $\mathrm{Sd} 1$ often includes abdominal cramps, fever and rectal pain. Less frequent complications of infection with Sd1 include sepsis, seizures, renal failure and the haemolytic uraemic syndrome (HUS) (19). Altered arachidonic acid metabolism has been implicated in the pathogenesis of renal injury in the HUS caused by shigatoxin (59). Approximately $5-15 \%$ of $\mathrm{Sd} 1$ cases are fatal. Shigatoxin works as enterotoxin, neurotoxin and cytotoxin. It is consist of two protein subunit: Subunit A perform as N-glycosidase which split adenin on ribosomes and inhibits proteosynthesis (40).

\section{Verotoxin}

The verotoxin, or shiga-like toxin family is a group of closely related toxins produced by certain pathogenic strains of Escherichia coli. Verotoxin-producing E. coli, especially of serotype O157:H7, cause a zoonotic food or waterborne enteric illness that is often associated with large epidemic outbreaks as well as the HUS, the leading cause of acute renal failure in children (27). These strains are a significant cause of human hemorrhagic colitis. In addition, they are both water borne and food borne and may also be transmitted from person-to-person by the oral-fecal route. In adults, illness caused by verotoxin may last several days. In children and the elderly, the illness can be fatal (20). Structure and mechanism of toxic action of verotoxin is equal shigatoxin but recently new pieces of knowledge were obtained. It has been known for some time that following the intracellular routing of shigatoxin and/or verotoxin to the endoplasmic reticulum and nuclear membrane, the toxins translocate into the cytoplasm and target ribosomes for damage. However, numerous recent studies have shown that these toxins trigger programmed cell death signaling cascades in intoxicated cells. The mechanisms of apoptosis induction by these toxins are newly emerging, and the data published to date suggest that the toxins may signal apoptosis in different cells types via different mechanisms (9).

\section{Cholera toxin}

Vibrio cholerae is a Gram-negative, curved rod bacteria. $V$ cholerae is responsible for approximately seven pandemic infections of extreme diarrhea and dehydration across the globe, resulting in millions of death throughout the centuries. $V$. cholerae as pathogen has been with mankind long before we were ever capable of detecting it, or understanding its mechanism of infection. Until recent times, the methods to confront this pathogen, and begin to understand its function were not available. 
The biochemistry of cholera toxin has been well characterized over recent years $(12,37)$. Cholera toxin is a heterohexameric protein, composed from five subunits $B$ and one subunit $\mathrm{A}$ ( $\mathrm{AB} 5$, choleragen), responsible for the symptoms produced by $V$. cholerae infection. In the first step of cell intoxication, the B-pentamer of the toxin binds specifically to the branched pentasaccharide moiety of ganglioside GM1 on the surface of target human intestinal epithelial cells.

The normal function of GM1 is not clearly understood but it has been implicated in numerous signal transduction pathways. Cholera toxin and GM1 complex show no major conformational change, but it is theorized about that the A subunit of the cholera toxin is inserted into the cell. This translocation is takes approximately 15 minutes and during this time it is theorized that the A subunit is cleaved along a disulfide bridge between $\mathrm{A} 1$ and $\mathrm{A} 2$, which keeps the protein inactive (36).

The A1 subunit of cholera toxin is the enzymatically active portion of the protein molecule, and it acts as an ADPribosyltransferase. It catalyzes a transfer of an ADP-ribose from an NAD+ to the arginine at location 187 in the alpha chain of the regulatory protein Gs (28). This ribosylation of Gs stabilizes the GTP bound form of the protein, lower its GTPase activity creating a near constitutively on signal for the generation of adenylyl cyclase, and therefore elevating cAMP levels. This high cAMP level results in the activation of the sodium pumps in the lumen of the cell through a cAMP dependent kinase pathway, forcing out $\mathrm{Na}+$ ions. This resultant electrochemical imbalance drives out $\mathrm{Cl}^{-}$and $\mathrm{H}_{2} \mathrm{O}$ to balance the $\mathrm{Na}+$ release. The net flow of fluid is now out of balance and the cells attempt to compensate for the dehydration through removal of fluid from the blood. This is the biochemical process responsible for the clinical characteristics of epidemic cholera infection. (14).

\section{Tetanus toxin}

The illness known as tetanus is caused by a neurotoxin produced by the anaerobic bacterium Clostridium tetani. It acts upon the presynaptic membranes of both central and peripheral nervous systems to block the release of neurotransmitters. Tetanus toxin is synthesised as a single polypeptide chain of $150 \mathrm{kDa}$, and undergoes proteolytic cleavage to produce a di-chain toxin consisting of the $\mathrm{N}$ - terminal 50 $\mathrm{kDa}$ fragment (light chain) linked by a disulphide bond to the $100 \mathrm{kDa}$ carboxy terminal fragment (heavy chain). Fragment $\mathrm{C}$ (the $\mathrm{C}$-terminal half of the heavy chain) retains ganglioside binding activity which is essential for the binding of the toxin to neuronal cells $(1,24)$. Tetanus toxin is likewise botulinum toxin a neurotoxin and their molecular structures and mechanism of action are very similar (65). The $\mathrm{LD}_{50}$ in unvaccinated humans is estimated at $<2.5$ $\mathrm{ng} / \mathrm{kg}(18)$. It is a powerful neurotoxin which may be fatal if inhaled or introduced into a wound. It causes muscle rigidity or spasms, paralysis, and death. If contact occurs, flush eyes, skin or wounds thoroughly with water. Seek me- dical attention, since supportive therapy will be required if symptoms occur. Immune globulin may also be a part of the medical treatment.

\section{Blue-green algae toxins}

Algae are small, often microscopic organisms. Blue-green algae called also cyanobacteria are the most primitive form of life. Only certain species of blue-green algae are capable of producing toxins and even these species are harmless most of the time. The presence of toxic algae is frequent reason for swiming prohibition in swiming pool or bathing in countryside (35). Toxic algae periodically bloom in freshwater aquatic sheet as well as in coastal waters, sometimes poisoning seabirds and marine mammals and interfering with economically important fisheries. These microorgamisms are rich source of different very toxic compounds. There are largely neurotoxins and hepatotoxins (53). Only microcystins and nodularin are peptides and only microcystins are on the „control list“ of the Australian Group.

\section{Microcystins}

The microcystins are a group of cyclic heptapeptide hepatotoxins produced by a number of cyanobacterial genera, the most notable of which is the widespread Microcystis from which the toxins take their name. Microcystins consist of a seven-membered peptide ring, which is made up of five non-natural amino acids and two natural amino acids. It is these two protein amino acids that distinguish microcystins from one another, while the other amino acids are more or less constant between variant microcystins. Using amino acid single letter code nomenclature, each microcystin is designated a name depending on the variable amino acids which complete their structure. The most common and potently toxic microcystin-LR contains the amino acids leucine $(\mathrm{L})$ and arginine $(\mathrm{R})$ in these variable positions.

Approximately 60 different microcystins was identified till this time. The general stucture of microcystins (Fig. 1) showing the variable amino acid positions " $\mathrm{X}$ " and "Y". The amino acids are delineated in this diagram and num-

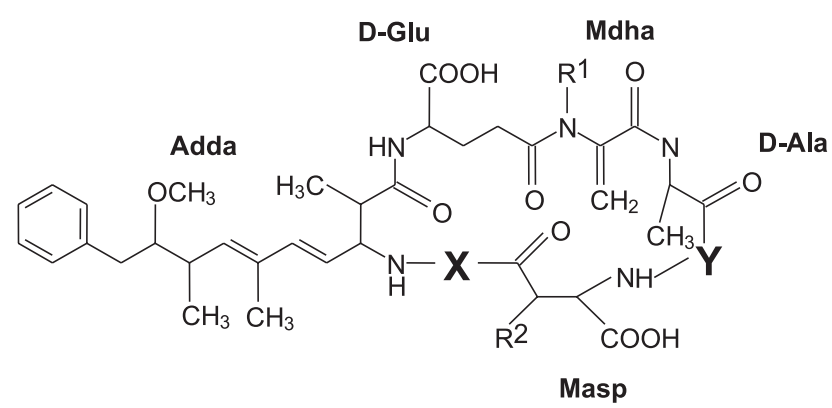

Fig. 1: The common chemical structure of microcystins. Adda $=3$-amino-9-methoxy-2,6,8-trimethyl-10-phenyldeca-4, 6-dienoic acid, D-Glu = D-glutamic acid, Mdha = N-methyldehydroalanine, D-Ala $=$ D-alanine, Masp $=$ D-methylaspartic acid, and $\mathrm{X}$ and $\mathrm{Y}$ are both variable $\mathrm{L}$-amino acids. 
bered according to the microcystin standard nomenclature. $\mathrm{R} 1$ and $\mathrm{R} 2$ are $\mathrm{H}$ in demethylated microcystins. These monocyclic heptapeptides are characterised by some invariant amino acids, including one of unusual structure - 3-amino9-methoxy-2,6,8-trimethyl-10-phenyldeca-4,6-dienoic acid (Adda) - which is essential for expression of toxicity. (53). Microcystins are chemically stable, but suffer biodegradation in reservoir waters. The most common member of the family, microcystin-LR ( $\mathrm{L}$ and $\mathrm{R}$ identifying the 2 variable amino acids, in this case leucine and arginine respectively) has an $\mathrm{LD}_{50}$ in mice and rats of $36-122 \mu \mathrm{g} / \mathrm{kg}$ by various routes, including aerosol inhalation. Although human illnesses attributed to microcystins include gastroenteritis and allergic/irritation reactions, the primary target of the toxin is the liver, where disruption of the cytoskeleton, consequent on inhibition of protein phosphatases 1 and $2 \mathrm{~A}$, causes massive hepatic haemorrhage. Microcystins are tight-binding inhibitors of these protein phosphatases, with inhibition constants in the nanomolar range or lower. Uptake of microcystins into the liver occurs via a carriermediated transport system, and several inhibitors of uptake can antagonise the toxic effects of microcystins. The most effective of these is the antibiotic rifampin, which protects mice and rats against microcystin-induced lethality when given prophylactically and, in some cases, therapeutically (11). More recent experimental evidence shows that microcystins may also act as liver tumor promoters in extremely small amounts. A tumor promoter does not initiate cancer formation but helps a previously developed cancer to survive. Poisoning symptoms may take 30 minutes to 24 hours to appear, depending upon the size of the animal affected and the amount of toxic bloom consumed. Microcystin toxicosis may include jaundice, shock, abdominal pain, weakness, nausea and vomiting, rapid and weak pulse and death (3).

\section{Conclusion}

Natural protein toxins represent a family of extremely potent toxic compounds, some of which, such as botulinum toxin is the most potent toxin known. The use of toxins for terrorist aims in the form of aerosols is a perfectly credible eventuality. A number of toxins could be used in a terrorist attack, including ricin and botulinum toxin. Progress in molecular biology caused that it is easy to produce and can lead to massive destruction. It will be possible produce whatever toxin in a short time. Preparedness among physicians, first responders, and public health officials is especially important because these agents are very dangerous.

\section{References}

1. Anderson MD, Fairweather N, Charles IG, Emsley P, Isaacs NW, MacDermott: Crystallographic characterization of tetanus toxin fragment C. J Mol Biol 1993 230:673-4.

2. Barbieri L, Zamboni M, Montanaro L, Sperti S, Stirpe F, Purification and properties of different forms of modeccin, the toxin of Adenia digitata. Separation of subunits with inhibitory and lectin activity. Biochem J 1980;185:203-10.
3. Brittain S, Mohamed ZA, Wang J, Lehmann VK, Carmichael WW, Rinehart KL, Isolation and characterization of microcystins from a river nile strain of oscillatoria tenuis Agardh ex Gomont. Toxicon 2000;38:1759-7.

4. Brynestad S, Granum PE, Clostridium perfringens and foodborne infections. Int J Food Microbiol 2002;74:195-202.

5. Castellino FJ, Prorok M. Conantokins: inhibitors of ion flow through the N-methylD-aspartate receptor channels. Curr Drug Targets 2000;1: 219-35.

6. Chambery A, Di Maro A, Monti MM, Stirpe F, Parente A. Volkensin from Adenia volkensii Harms (kilyambiti plant), a type 2 ribosome-inactivating protein. Eur J Biochem 2004;271:108-17.

7. Chen YL, Chow LP, Tsugita A, Lin JY. The complete primary structure of abrina B chain. FEBS Lett 1992;309:115-8.

8. Cherington M. Botulism: update and review. Semin Neurol 2004;24:155-63.

9. Cherla RP, Lee SY, Tesh VL. Shiga toxins and apoptosis. FEMS Microbiol Let. 2003;228:159-66.

10. Clark K. The Chemical Weapons Convention: Chemical and Toxin Warfare Agents and Disarmament. Royal Military College of Science, Cranfield University, August 1997.

11. Dawson RM. The toxicology of microcystins. Toxicon 1998;36:953-62.

12. De Haan L, Hirst TR. Cholera toxin: a paradigm for multi-functional engagement of cellular mechanisms (Review). Mol Membr Biol 2004;21:77-92.

13. Donelli G, Fiorentini C, Matarrese P, Falzano L, Cardines R, Mastrantonio P, Payne DW, Titball RW. Evidence for cytoskeletal changes secondary to plasma membrane functional alterations in the in vitro cell response to Clostridium perfringens epsilon-toxin. Comp Immunol Microbiol Infect Dis 2003;26:145-56.

14. Enomoto K, Gill DM. Cholera toxin activation of adenylate cyclase. Roles of nucleoside triphosphates and a macromolecular factor in the ADP ribosylation of the GTP-dependent regulatory component. J Biol Chem 1980;255:1252-8.

15. Fegan D, Andresen D. Conus geographus envenomation. Lancet 1997;349:1672.

16. Freer JH, Arbuthnott JP. Toxins of Staphylococcus aureus. Pharmacol Ther 1982;19:55-106.

17. Gasperi-Campani A, Barbieri L, Lorenzoni E, Montanaro L, Sperti S, Bonetti E. Modeccin, the toxin of Adenia digitata. Purification, toxicity and inhibition of protein synthesis in vitro. Biochem J 1978;174:491-6.

18. Gill DM. Bacterial toxins: a table of lethal amounts. Microbiol Rev 1982;46: 86-94.

19. Gordjani N, Sutor AH, Zimmerhackl LB, Brandis M. Hemolytic uremic syndromes in childhood. Semin Thromb Hemost 1997;23:281-93.

20. Gransden WR, Damm MA, Anderson JD, et al. Further evidence associating hemolytic-uremic syndrome with infection by Verotoxin-producing Escherichia coli 0157:H7. J Infect Dis 1986;154:522-4.

21. Greenfield RA, Brown BR, Hutchins JB et al. Microbiological, biological, and chemical weapons of warfare and terrorism. Am J Med Sci 2002;323:326-40.

22. Haas LF. Emil Adolph von Behring (1854-1917) and Shibasaburo Kitasato (1852-1931). J Neurol Neurosurg Psychiatry 2001;71:62.

23. Hartley MR, Lord JM. Cytotoxic ribosome-inactivating lectins from plants. Biochim Biophys Acta 2004;1701:1-14.

24. Helting TB, Zwisler O, Wiegandt H. Structure of tetanus toxin. II. Toxin binding to ganglioside. J Biol Chem. 1977;252:194-8.

25. Hildebrand A, Pohl M, Bhakdi S. Staphylococcus aureus alpha-toxin. Dual mechanism of binding to target cells. J Biol Chem 1991;266:17195-200.

26. Holmes RK: Biology and molecular epidemiology of diphtheria toxin and the tox gene. J Infect Dis 2000;181, Suppl 1:156-67.

27. Karmali MA. Infection by Shiga toxin-producing Escherichia coli: an overview. Mol Biotechnol 2004;26:117-22.

28. Kassis S, Hagmann J, Fishman PH, Chang PP, Moss J. Mechanism of action of cholera toxin on intact cells. Generation of A1 peptide and activation of adenylate cyclase. J Biol Chem 1982;257:12148-52.

29. Katzin BJ, Collins EJ, Robertus JD. Structure of ricin A-chain at 2.5 A. Proteins 1991;10:251-9.

30. Kimura M, Sumizawa T, Funatsu G: The complete amino acid sequences of the B-chains of abrin-a and abrin-b, toxic proteins from the seeds of Abrus precatorius. Biosci Biotechnol Biochem 1993;57:166-9.

31. Krauspenhaar R, Eschenburg S, Perbandt M et al. Crystal structure of mistletoe lectin I from Viscum album. Biochem Biophys Res Commun 1999;257:418-24.

32. Lewis RJ. Conotoxins as selective inhibitors of neuronal ion channels, receptors and transporters. IUBMB Life 2004;56:89-93.

33. Lord JM, Roberts LM, Robertus JD. Ricin: structure, mode of action, and some current applications. FASEB J 1994;8:201-8.

34. Low DK, Freer JH, Arbuthnott JP, Mollby R, Wadstrom T. Consequences of sphingomyelin degradation in erythrocyte ghost membranes by staphylococcal beta-toxin (sphingomyelinase C). Toxicon 1974;12:279-85.

35. Mátlová J, Krejčí V, Patočka J. Cyanotoxins and their effect on human health (Article in Czech). Kontakt 2004;6(1): 43-51.

36. Merritt EA, Kuhn P, Sarfaty S, Erbe JL, Holmes RK, Hol WG. The 1.25 A resolution refinement of the cholera toxin B-pentamer: evidence of peptide backbone strain at the receptor-binding site. J Mol Biol 1998;282:1043-59. 
37. Merritt EA, Sarfaty S, van den Akker F, L'Hoir C, Martial JA, Hol WG. Crystal structure of cholera toxin B-pentamer bound to receptor GM1 pentasaccharide. Protein Sci 1994;3:166-75

38. Montfort W, Villafranca JE, Monzingo AF et al. The three-dimensional structure of ricin at 2.8 A. J Biol Chem 1987;262:5398-403.

39. Morris KN, Wool IG. Analysis of the contribution of an amphiphilic alpha-helix to the structure and to the function of ricin A chain. Proc Natl Acad Sci USA 1994;91:7530-3.

40. O'Brien AD, Tesh VL, Donohue-Rolfe A, et al. Shiga toxin: biochemistry, genetics, mode of action, and role in pathogenesis. Curr Topics Microbiol Immunol 1992;180:65-94.

41. Ochi S, Oda M, Nagahama M, Sakurai J. Clostridium perfringens alpha-toxin-induced hemolysis of horse erythrocytes is dependent on $\mathrm{Ca}^{2+}$ uptake. Biochim Biophys Acta 2003;1613:79-86.

42. Ohizumi Y, Matsunaga K. Chemical structures and the mechanism of action of peptide toxins from cone shells (Article in Japanese). Tanpakushitsu Kakusan Koso 2001;46, Suppl 14:449-54.

43. Olsnes S, Haylett T, Sandvig K. The toxic lectin modeccin. Methods Enzymol 1982;83:357-62.

44. Olsnes S, Kozlov JV: Ricin. Toxicon 2001;39:1723-8.

45. Olsnes S, Pihl A. Kinetics of binding of the toxic lectins abrin and ricin to surface receptors of human cells. J Biol Chem 1976;251:3977-84.

46. Olsnes S, Sandvig K, Eiklid K, Pihl A. Properties and action mechanism of the toxic lectin modeccin: interaction with cell lines resistant to modeccin, abrin, and ricin. J Supramol Struct 1978;9:15-25.

47. Olsnes S. The history of ricin, abrin and related toxins. Toxicon. 2004;44:361-70.

48. Patočka J. Abrin and ricin - two dangerous poisonous proteins. ASA Newsletter 2001;85:205-8.

49. Patočka J, Špliňo M. Botulinum toxin: from poison to medicinal agent. ASA Newsletter 2002;88:14-9.

50. Patočka J, Špliňo M, Měrka V. Botulism and bioterrorism: How serious is this problem? Acta Medica (Hradec Kralove) 2005;48:23-8.

51. Patočka J, Středa L. Brief review of natural nonprotein neurotoxins. ASA Newsletter 2002;89:16-24.

52. Patočka J, Středa L. Plant toxic proteins and their current significance for warfare and medicine. J Appl Biomed 2003;1:141-7.

53. Patočka J. The toxins of cyanobacteria. Acta Medica (Hradec Kralove) 2001; 44:69-75

54. Patocka J: Toxicological characteristic of ricin (Article in Czech). Voj Zdrav Listy 1998;67:166-8.
55. Petit L, Gibert M, Gourch A, Bens M, Vandewalle A, Popoff MR. Clostridium perfringens epsilon toxin rapidly decreases membrane barrier permeability of polarized MDCK cells. Cell Microbiol. 2003;5:155-64.

56. Refsnes K, Haylett T, Sandvig K, Olsnes S. Modeccin - a plant toxin inhibiting protein synthesis. Biochem Biophys Res Commun 1977;79:1176-83.

57. Robinson RF, Nahata MC. Management of botulism. Ann Pharmacother 2003;37:127-31.

58. Rutenber E, Robertus JD. Structure of ricin B-chain at 2.5 A resolution. Proteins 1991;10:260-9.

59. Schmid DI, Kohan DE. Effect of shigatoxin-1 on arachidonic acid release by human glomerular epithelial cells. Kidney Int 2001;60:1026-36.

60. Sharon N, Lis H. Cell-agglutinating and sugar-specific proteins. Science 1972;177:949-59.

61. Slater LN, Greenfield RA. Biological toxins as potential agents of bioterrorism. J Okla State Med Assoc 2003;96:73-6.

62. Smedley JG, Fisher DJ, Sayeed S, Chakrabarti G, McClane BA. The enteric toxins of Clostridium perfringens. Rev Physiol Biochem Pharmacol 2004;152:183-204.

63. Stirpe F. Ribosome-inactivating proteins. Toxicon. 2004;44:371-83.

64. Thelestam M, Blomqvist L. Staphylococcal alpha toxin-recent advances. Toxicon 1988;26:55-65.

65. Turton K, Chaddock JA, Acharya KR. Botulinum and tetanus neurotoxins: structure, function and therapeutic utility. Trends Biochem Sci 2002;27:552-8.

66. Wang KY, Xu Q. Lectins and Toxins. Sheng Wu Hua Xue Yu Sheng Wu Wu Li Xue Bao (Shanghai) 2000;32:201-5.

67. Zapor M, Fishbain JT. Aerosolized biologic toxins as agents of warfare and terrorism. Respir Care Clin N Am 2004;10:111-22.

Submitted June 2005.

Accepted March 2006.

Prof. RNDr. Jiři Patočka, DrSc., University of Defence,

School of Military Health Sciences,

Department of Toxicology, 50001 Hradec Králové, Czech Republic. e-mail: prof.patocka@gmail.com 